\title{
POVOS INDÍGENAS E AÇÕES AFIRMATIVAS: ASPECTOS SOBRE A IMPLEMENTAÇÃO DA LEI N. 12.711/2012 PELAS INSTITUIÇÕES DE ENSINO FEDERAIS
}

\author{
Isabele Batista de Lemos ${ }^{1}$
}

\section{Resumo}

No presente artigo, analisa-se o sistema de reserva de vagas instituído pela Lei. n. 12.711/2012 para povos indígenas nas universidades e nos institutos técnicos federais. No contexto das políticas afirmativas voltadas a esse grupo vulnerável e das reivindicações do movimento indígena brasileiro, discute-se o espaço deixado pela Lei n. 12.711 para a atuação das instituições de ensino federais, no sentido de ajustarem os critérios de ingresso dos indígenas às especificidades desses povos, de modo a tornarem a medida afirmativa adequada e eficaz. Neste sentido, propõe-se que as universidades e os institutos técnicos de nível médio, no âmbito de sua autonomia, possam adotar o método de identificação dos candidatos segundo os parâmetros da Convenção 169 da OIT, bem como realizar processo seletivo diferenciado para os estudantes indígenas.

Palavras-chave: Povos indígenas. Ações afirmativas. Lei n. 12.711/2012. Convenção 169 OIT. Seleção diferenciada.

\section{INTRODUÇÃO}

A Constituição de 1988 inaugurou um novo marco jurídico de reconhecimento e valorização da diversidade sociocultural brasileira, conferindo proteção especial aos povos indígenas enquanto sujeitos coletivos de direitos, que possuem o direito a preservar suas diferenças.

Atualmente, o movimento indígena brasileiro prioriza o acesso à educação e aos conhecimentos científicos dominantes como um instrumento para que possam protagonizar sua própria história, defender seus direitos e recuperar sua autonomia.

Neste contexto, as ações afirmativas consistentes na reserva de vagas para indígenas em universidades e outras instituições de ensino visam a proporcionar igualdade de oportunidades no acesso à educação, levando em conta as razões históricas que excluíram e segregaram os povos indígenas. A aprovação da Lei n. 12.711 vem

\footnotetext{
${ }^{1}$ Mestranda no Programa de Pós-Graduação em Direito da Universidade Federal do Pará, na linha de pesquisa "Direitos Humanos e Inclusão Social". E-mail: isabele174@hotmail.com
} 
afirmar, nesse sentido, a ideia de democratização do ensino superior público, ao estabelecer a reserva de vagas para esse grupo vulnerável.

O objetivo do presente artigo é refletir sobre a implementação das cotas para indígenas previstas na Lei n. 12.711, analisando-se o espaço de autonomia deixado às instituições de ensino federais para definirem os critérios de ingresso e seleção dos candidatos indígenas, conforme as peculiaridades e as reivindicações desses povos, e no intuito de assegurar-se a adequação e a efetividade da política afirmativa.

\section{POVOS INDÍGENAS BRASILEIROS CONTEMPORÂNEOS}

De acordo com os dados do Censo Demográfico 2010, realizado pelo Instituto Brasileiro de Geografia e Estatística (IBGE), existem no Brasil 896 mil pessoas que pertencem à população indígena - o que corresponde a $0,4 \%$ da população brasileira ${ }^{2}$ - incluindo aqueles que se declararam indígenas no quesito cor ou raça e os residentes em terras indígenas que não se declararam, mas se consideraram indígenas. Deste total de 896 mil pessoas, $63,8 \%$ vivem na área rural e os outros 36,2\% nas cidades, sendo que 517 mil (ou 57,7\%) moram em terras indígenas oficialmente reconhecidas. ${ }^{3}$

As informações coletadas no Censo 2010 revelaram, ainda, tanto nas terras indígenas quanto fora delas, a existência de 305 etnias e de 274 línguas indígenas ${ }^{4}$, estando a população indígena distribuída em todas as regiões do país, concentrando-se, porém, na região da Amazônia Legal.

Estes números demonstram que a população indígena, além de representar parcela significativa da população brasileira, constitui-se num grupo heterogêneo, composto por diversos povos e etnias, que está espalhado pelo território nacional, vivendo não apenas no meio rural ou em terras indígenas, mas também nos centros urbanos.

Vale ressaltar que existem ainda povos indígenas não contabilizados nestes dados do IBGE, quais sejam, os denominados "índios isolados", que não mantêm qualquer contato com o restante da sociedade brasileira, e aqueles denominados "emergentes", que estão em vias de reafirmação étnica após anos de dominação e repressão cultural.

Longe de serem resquícios históricos de uma sociedade do passado, numa visão estereotipada que, ora idealiza o índio como ser ingênuo, protetor da floresta, ora como ser selvagem e preguiçoso, os povos indígenas brasileiros de hoje são sobreviventes e resistentes da história de colonização europeia, que estão em franca

\footnotetext{
${ }^{2}$ Disponível em: <http://indigenas.ibge.gov.br/images/indigenas/estudos/indigena_censo2010.pdf>. Acesso em: 01.07.13.

${ }_{3}^{3}$ Disponível em: <http://indigenas.bge.gov.br/estudos-especiais-3/o-brasil-indigena/os-indigenas-no-censo- demografico2010>. Acesso em: 01.07.13.

4 Disponível em: <http://saladeimprensa.ibge.gov.br/noticias?view=noticia\&id=1\&busca=1\&idnoticia=2360>. Acesso em: 01.07 .13
} 
recuperação do orgulho e da autoestima identitária, tendo como desafio a consolidação de um espaço digno na história e na vida multicultural do país. (LUCIANO, 2006).

Conforme explica Luciano (2006), a expressão genérica "índios" designa uma multiplicidade de formas de vida coletiva e individual, agregando povos, etnias e culturas diversos, e, neste sentido, viabiliza uma marca identitária capaz de unir e fortalecer a articulação e mobilização destes povos originários na luta por direitos e interesses comuns.

Com efeito, os povos indígenas, embora constituam um grupo socioculturalmente diversificado e heterogêneo, enfrentam inúmeras dificuldades e desafios semelhantes, relacionados à luta pela autoafirmação identitária diante de uma sociedade ainda permeada por ranços de uma visão integracionista, que não respeita o indígena nas suas especificidades e diferenças. Apesar de o movimento indígena já ter conquistado enormes avanços no campo do reconhecimento de direitos específicos, notadamente a partir da Constituição de 1988, ainda persiste um quadro de exclusão social destes sujeitos, em virtude de concepções preconceituosas e estigmatizantes que obstaculizam a efetivação da sua plena cidadania.

Os problemas que atualmente enfrentam na consolidação de uma cidadania plena e diferenciada têm suas raízes no projeto político civilizatório europeu de dominação sobre os povos originários destas terras. Ao longo de todo o período colonial brasileiro, os indígenas sofreram todo tipo de violência por parte do "homem branco" - como a espoliação de suas terras, o cativeiro, a catequização e conversão à fé cristã nos aldeamentos, e o próprio extermínio - sob o manto de uma concepção de mundo etnocêntrica, que sempre desqualificou o "índio" como ser inferior e a sua cultura como primitiva.

Esta concepção predominou por muito tempo, acompanhada do extermínio físico e cultural dos povos indígenas, chegando ao ponto de se acreditar, desde o final do século XIX, que a população indígena estava fadada à extinção, na medida em que os indígenas representariam um estágio provisório, isto é, "deveriam evoluir e perder a sua condição de índios, sendo definitivamente assimilados pela sociedade envolvente”. (ARAÚJO, 2006, p. 29).

A ideia de integração e assimilação foi a diretriz básica da política indigenista adotada pelo Estado brasileiro desde então. De fato, o revogado Código Civil de 1916 considerava os "silvícolas" relativamente incapazes para certos atos da vida civil, determinando que eles deveriam ficar sujeitos ao regime tutelar até a sua completa adaptação à "civilização".

Neste contexto, no final da década de 1960, foi criada a Fundação Nacional do Índio (FUNAI), órgão com competência para exercer o papel de verdadeiro tutor dos índígenas e, dentre outras finalidades, "promover a educação de base apropriada do índio visando à sua progressiva integração na sociedade nacional” (art. 1º inc. V, da Lei n. 5.371/1967). 
O Estatuto do Índio (Lei n. 6.001/1973) seguiu esta mesma orientação, anunciando o seu propósito logo no primeiro artigo: integrar os "índios ou silvícolas" à comunhão nacional, assimilando-os de forma harmoniosa e progressiva. Este diploma legal classifica os índios em três categorias, a saber: "isolados", "em vias de integração" e "integrados", reconhecendo a estes últimos o pleno exercício dos direitos civis. Além disso, dedica um capítulo inteiro ao instituto da assistência ou tutela, incumbida à União, que a exercerá através do órgão tutelar competente. Nas palavras de Araújo (2006, p. 32),

o objetivo do Estatuto era fazer com que os índios paulatinamente deixassem de ser índios. Tratava-se, portanto, de uma lei cujos destinatários eram como "sujeitos em trânsito", portadores, por isso mesmo, de direitos temporários, compatíveis com a sua condição e que durariam apenas e enquanto perdurasse essa mesma condição.

Embora o Estatuto do Índio ainda esteja formalmente em vigor, diversos dos seus dispositivos não foram recepcionados pela Constituição de 1988, que trouxe uma série de inovações e de significativos avanços no tratamento da questão indígena. A Carta Política de 1988 consagrou um capítulo específico à proteção dos direitos dos povos indígenas, reconhecendo-lhes sua "organização social, costumes, línguas, crenças e tradições, e os direitos originários sobre as terras que tradicionalmente ocupam, competindo à União demarcá-las, proteger e fazer respeitar todos os seus bens." (art. 231, caput).

Acerca da proteção constitucional conferida aos povos indígenas, aos quais foram assegurados direitos culturais e territoriais especiais, Santilli (2005) afirma que esses direitos devem ser compreendidos sob o prisma do multiculturalismo, que se baseia no reconhecimento da diferença e no direito à diferença. A Carta de 1988, desse modo, rompeu com o modelo assimilacionista e homogeneizador até então vigente, reconhecendo direitos coletivos aos povos indígenas como povos cultural e etnicamente diferenciados. De acordo com a mencionada autora, não mais subsiste, frente à nova ordem constitucional, a classificação dos índios em "isolados" e “integrados" prevista no Estatuto do Índio:

Em face da nova perspectiva constitucional, que assegura e valoriza a diversidade cultural, as distinções entre índios "isolados" e "integrados" estabelecidas no Estatuto do Índio estão superadas. A Constituição não discrimina categorias diferentes de índios, para efeito de exercício de seus direitos, e a lei ordinária não pode fazê-lo. Ademais, a condição de índio deixou de ser transitória para ser permanente, já que o objetivo constitucional é assegurar a diversidade, e não a homogeneidade. (SANTILLI, 2005, p. 136).

Na mesma linha de pensamento, Araújo (2006) explica que a Constituição de 1988 reconheceu aos povos indígenas direitos coletivos e permanentes, criando as bases para a consolidação de uma sociedade pluriétnica e multicultural, na qual os povos indígenas têm o direito de continuar a existir como povos que são, independentemente do grau de contato ou de interação com o restante da sociedade brasileira. 
A valorização da diversidade sociocultural que orienta o texto constitucional pressupõe a concretização de uma cidadania em harmonia com os direitos culturais. Neste sentido, o art. $210, \$ 2^{\circ}$, revela a preocupação do legislador constituinte em assegurar a transmissão das línguas indígenas às novas gerações, determinando que "o ensino fundamental regular será ministrado em língua portuguesa, assegurada às comunidades indígenas também a utilização de suas línguas maternas e processos próprios de aprendizagem”. Por sua vez, o art. $215, \$ 1^{\circ}$, diz que é dever do Estado proteger as manifestações culturais dos povos indígenas e de outros grupos integrantes da sociedade brasileira.

A Carta Política inovou também ao reconhecer a capacidade processual dos índios, de suas comunidades e organizações na defesa dos seus próprios direitos e interesses, atribuindo ao Ministério Público o dever de garantir os direitos indígenas e de intervir em todos os processos judiciais que digam respeito a tais direitos e interesses.

A partir do advento do novo paradigma constitucional, portanto, os povos indígenas, de sujeitos considerados transitórios e incapazes - que necessitavam ser tutelados pelo Estado, segundo a lógica integracionista de assimilação cultural consolidada no Estatuto do Índio - passaram a ser protagonistas, sujeitos coletivos e sujeitos de direitos e de cidadania brasileira. (LUCIANO, 2006).

O Código Civil de 2002 também ofereceu tratamento mais positivo aos índios, estatuindo que o tema de sua capacidade para a prática dos atos da vida civil deverá ser regulado por legislação especial. Conforme explica Araújo (2006, p. 58):

O novo Código Civil extirpou de seu texto a menção à relativa capacidade dos índios fixada pelo antigo Código de 1916. O novo Código tampouco fala em tutela e, de quebra, varre de seu vocabulário o ultrapassado termo "silvícola" que, de significado discriminatório e inadequado, durante anos foi utilizado pela legislação.

No entanto, até o momento, ainda não foi produzida uma legislação específica em substituição ao Estatuto do Índio, que regulamentasse temas como a capacidade civil dos índios, a proteção aos conhecimentos tradicionais e a demarcação de terras. Desde 1990, tramitam no Congresso Nacional vários Projetos de Lei propondo a revisão do Estatuto do Índio e a regulamentação de diversos aspectos da Constituição relacionados aos direitos indígenas. (ARAÚJO, 2006).

O tema da capacidade civil dos índios é, com efeito, uma questão central a ser enfrentada na reformulação do Estatuto. Diante da nova ordem constitucional, não se pode mais admitir que os indígenas não sejam plenamente capazes de determinarem suas próprias vontades e que as relações de contato mantidas com a sociedade envolvente sejam intermediadas por um órgão tutor. Segundo Araújo (2006, p. 47), "a condição de tutelados cerceia sua livre expressão política, a administração direta dos seus territórios, seu acesso aos serviços públicos, ao mercado de trabalho, às linhas oficiais de crédito etc". 
Existem propostas que pretendem o fim do instituto da tutela e da caracterização dos índios como relativamente incapazes, sem olvidar da necessidade de conferir-lhes um tratamento jurídico diferenciado, em razão de suas especificidades culturais, mediante a criação de mecanismos de proteção no que diz respeito às relações com particulares e com o próprio Estado. (ARAÚJO, 2006). De acordo com Souza Filho (1998, p. 99), é necessário pensar num regime de proteção diferenciado, "que não trate os índios como indivíduos deficientes, mas como pessoas que necessitam de estatuto jurídico especial".

A cidadania diferenciada, segundo Luciano (2006), significa que os povos indígenas são titulares dos mesmos direitos que possuem os cidadãos brasileiros, além dos direitos específicos relativos à sua cultura, às tradições, aos valores, aos conhecimentos e aos ritos. Assim, o autor afirma que "somente o diálogo intercultural efetivo é capaz de possibilitar a coexistência das lógicas da etnia e da cidadania em um mesmo espaço social e territorial”. (LUCIANO, 2006, p. 89).

É fundamental compreender que a cidadania brasileira tem para os povos indígenas um sentido de inclusão, de acesso aos benefícios que a sociedade nacional pode lhes oferecer (como a tecnologia da informação, por exemplo), além de participação nas decisões que lhes dizem respeito. (LUCIANO, 2006).

Desta forma, uma nova forma de proteção aos povos indígenas precisa ser esboçada, pautada em uma necessária convivência harmônica de universos culturais diferentes, que garanta os direitos desses povos e respeite a sua autonomia na gestão dos próprios modos de vida. Está mais do que na hora de superarmos visões estereotipadas e preconceituosas dos índios e passar a concebê-los como sujeitos de direitos, segundo os parâmetros de uma cidadania diferenciada, baseada em direitos específicos e condizentes com o respeito à diferença.

\section{EDUCAÇÃO ESCOLAR INDÍGENA}

Conforme explica Luciano (2006), as comunidades indígenas possuem métodos próprios de educação, referentes aos processos de transmissão e de produção dos seus conhecimentos tradicionais. Ao lado da apropriação destes saberes, os índios têm o direito de adquirirem conhecimentos não indígenas por meio da escola, instituição que lhes proporciona o acesso a outros conhecimentos, que se tornam necessários para reforçar seus projetos socioculturais na sociedade global. Nas palavras do mencionado autor:

Diante das necessidades de um mundo cada vez mais globalizado, os índios julgam que a educação escolar, quando apropriada por eles e direcionada para atender às suas necessidades atuais, pode ser um instrumento de fortalecimento das culturas e das identidades indígenas e um possível canal de conquista da desejada cidadania, entendida como direito de acesso aos bens e aos valores materiais e imateriais do mundo moderno. (LUCIANO, 2006, p. 129). 
Como foi visto, a Constituição Federal de 1988 reconheceu expressamente às comunidades indígenas a utilização de suas línguas maternas e processos próprios de aprendizagem, o que propiciou o surgimento de escolas com professores indígenas e a utilização de materiais didáticos bilíngues.

Obedecendo ao comando constitucional, a Lei de Diretrizes e Bases da Educação Nacional (Lei 9.394/1996), em seus artigos 78 e 79, estabelece que compete ao Estado oferecer aos índios uma educação escolar bilíngüe, ou seja, simultaneamente em português e nas línguas indígenas. Os dispositivos legais têm por objetivo proporcionar aos índios e suas comunidades "a recuperação de suas memórias históricas, a reafirmação de suas identidades étnicas e a valorização de suas línguas e ciências", assim como, "o acesso às informações, conhecimentos técnicos e científicos da sociedade nacional e demais sociedades indígenas e não índias" (art. 78, inc. I e inc. II).

Os dados do Censo Escolar realizado nos últimos anos indicam que, na última década, houve progressos significativos na política para a educação básica indígena, notadamente em termos quantitativos, com o crescimento do número de escolas e de estudantes indígenas, tanto no nível fundamental quanto no nível médio. ${ }^{5}$

Não obstante, o grande desafio que ora se apresenta é garantir a qualidade e a especificidade da educação escolar básica indígena, a qual, nas palavras de Brito Filho (2013, p. 102), “ainda engatinha, ou seja, não oferece aos alunos indígenas, no presente, condições objetivas que o capacitem a disputar o ingresso nas instituições de ensino [superior]".

Com efeito, muitas escolas indígenas têm uma infra-estrutura precária e algumas nem existem fisicamente, funcionando debaixo de árvores, na maloca do cacique, conforme explica Gersem Baniwa, coordenador-geral de educação escolar indígena do Ministério da Educação. ${ }^{6}$ Além disso, dentre outras medidas urgentes, é necessário avançar no processo de formação superior de professores indígenas, de modo que possam obter uma formação adequada para lecionar nas escolas indígenas, e ampliar a produção de materiais didáticos específicos para as diferentes comunidades.

Observa-se que o Brasil possui uma legislação voltada à educação escolar indígena, em suas linhas gerais, bastante progressista, a qual reconhece os processos particulares de aprendizagem das diferentes comunidades indígenas. Todavia, sua efetiva implementação ainda esbarra numa série de empecilhos de ordem administrativa, técnica, financeira e de capacitação de recursos humanos, que afetam a qualidade do ensino oferecido.

A melhora substancial na qualidade do ensino médio em particular perpassa pela garantia de autonomia das comunidades indígenas na gestão dos projetos educacionais, tendo em vista suas necessidades e seus legítimos projetos socioculturais. A fase do ensino médio não deve ser interpretada como a preparação para o "mundo

\footnotetext{
${ }_{5}^{5}$ Disponível em: <http://download.inep.gov.br/download/censo/2008/Educacao_Indigena_estudo2008.pdf>. Acesso em: 09.07.13.

${ }^{6}$ Disponível em: <http://www.mudamundo.com.br/atualidades_det.php?id=347>. Acesso em: 09.07.13.
} 
civilizado", mas, ao contrário, deve preservar a vertente intercultural, bilíngue e diferenciada característica do ensino fundamental.

Importa ressaltar neste ponto que o Censo Demográfico 2010 do IBGE, no que diz respeito aos níveis educacionais básicos, revelou que a taxa de alfabetização das pessoas indígenas de 15 anos ou mais de idade está abaixo da média nacional, sendo que, nas terras indígenas, $32,3 \%$ ainda são analfabetos. ${ }^{7}$

Estes dados parecem indicar que a proposta de educação escolar indígena diferenciada como instrumento para a efetivação de uma cidadania igualmente diferenciada ainda é um grande desafio que se põe diante da sociedade brasileira. Neste contexto, os indígenas que pretendem ingressar no ensino superior enfrentam uma série de dificuldades, em razão das condições materiais ainda insatisfatórias da educação escolar indígena, estando, portanto, numa situação de desigualdade em relação aos outros candidatos.

Os povos indígenas anseiam por educação básica de qualidade, que, ao mesmo tempo, respeite a metodologia pedagógica de cada povo, seguindo a dinâmica da comunidade. Também querem ter garantidos o acesso e a permanência no ensino superior. (BAPTISTA, 2012). Em entrevista aberta realizada em 2007 com o líder guarani Almires Martins Machado, Baptista (2012, p. 207) indagou os motivos pelos quais os indígenas querem ter acesso à educação "branca” e aquele respondeu:

Que o principal motivo para os indígenas buscarem o acesso ao ensino é o futuro incerto desses povos. Com o conhecimento dominante, eles poderão verificar quais os instrumentos mais adequados a serem usados na luta por seus direitos; e não somente isso: os indígenas não querem mais que pessoas estranhas ao seu povo escrevam sua história; eles querem escrever sua própria história.

\section{Ações afirmativas e as inovações trazidas pela Lei n. 12.711/2012}

De acordo com Gomes (2001, p. 40), as ações afirmativas correspondem a um conjunto de políticas públicas e privadas de caráter compulsório, facultativo ou voluntário, concebidas com vistas ao combate à discriminação racial, de gênero e de origem nacional, bem como para corrigir os efeitos presentes da discriminação praticada no passado, tendo por objetivo a concretização do ideal de efetiva igualdade de acesso a bens fundamentais como a educação e o emprego.

A ideia de igualdade material ou real está na base dos programas de ação afirmativa, na medida em que, na busca de um equilíbrio, de uma efetiva igualdade de oportunidades, é dispensado um tratamento desigual àqueles que se encontram em um contexto de desigualdade, e, portanto, em condições de desvantagem em

\footnotetext{
7 Disponível em: <http://indigenas.ibge.gov.br/estudos-especiais-3/o-brasil-indigena/caracteristicasocidemograficas- edomiciliares $>$. Acesso em: 01.07.13.
} 
relação ao restante da coletividade. Trata-se, pois, de mecanismos de inclusão social, por meios dos quais o Estado (principal, mas não exclusivamente) adota uma postura ativa, promocional, no combate à discriminação.

Neste raciocínio, Brito Filho (2013) esclarece que as ações afirmativas compõem um modelo próprio de combate à discriminação e caracterizam-se pela edição de normas que criam condições diferenciadas de acesso a determinados bens, em oposição à exclusão causada às pessoas pelo seu pertencimento a grupos vulneráveis, cujo objetivo consiste em proporcionar uma igualdade real entre os indivíduos.

A Constituição Federal de 1988 elencou como objetivos fundamentais da República a construção de uma sociedade justa, a erradicação da pobreza e da marginalização, a redução das desigualdades sociais e regionais, e a promoção do bem de todos, sem preconceitos de origem, raça, sexo, cor, idade e quaisquer outras formas de discriminação.

Nota-se então que a implementação pelo Estado e pela sociedade de medidas que visem proporcionar uma efetiva igualdade entre os indivíduos por meio da criação de condições diferenciadas de acesso a bens e oportunidades se apresenta na Carta Política não como uma faculdade, mas como uma imposição necessária para a concretização dos objetivos fundamentais nela consagrados, cujo fundamento maior reside na dignidade da pessoa humana.

A igualdade material, conforme lição de Piovesan (2006), além de corresponder ao ideal de justiça social e distributiva (igualdade orientada pelo critério socioeconômico), corresponde também ao ideal de justiça enquanto reconhecimento de identidades (igualdade orientada por critérios como os de gênero, orientação sexual, idade, raça, etnia e demais critérios).

Santos (2006) explica que desigualdade e exclusão são conceitos distintos: enquanto a desigualdade é um fenômeno socioeconômico, a exclusão é sobretudo um fenômeno cultural e social. No sistema de desigualdade, assentado paradoxalmente no essencialismo da igualdade, a pertença dá-se pela integração subordinada. Por sua vez, no sistema de exclusão, assentado no essencialismo da diferença, a pertença dá-se pela exclusão, isto é, pertence-se pela forma como se é excluído, segregado.

Neste sentido, o mencionado autor afirma que as políticas de igualdade e de identidade devem ser articuladas segundo o imperativo de que "temos o direito a ser iguais sempre que a diferença nos inferioriza; temos o direito a ser diferentes sempre que a igualdade nos descaracteriza". (SANTOS, 2006, p. 313).

A situação atual de vulnerabilidade dos povos indígenas resulta de um longo processo histórico pautado na ideologia da integração, da assimilação, que situou estes povos no sistema de exclusão. As políticas afirmativas voltadas para povos indígenas, notadamente no âmbito da educação, constituem uma estratégia destinada a promover a inclusão social destes grupos historicamente segregados por motivos étnicos e culturais, partindo-se da premissa de que, ao lado do direito à igualdade, existe o direito à diferença. E o reconhecimento da diferença 
pressupõe a consideração desta categoria vulnerável a partir das especificidades e peculiaridades de sua condição social.

Conforme explica Baptista (2012, p. 205), os povos indígenas podem ser identificados como minoria ou grupo vulnerável, na medida em que constituem:

Grupos étnicos com modo de vida diferente e traços culturais marcantes que os diferem da totalidade da população e que estão em cristalina situação de desnível em igualdade de oportunidades, quando comparados aos demais brasileiros.

Atualmente, o movimento indígena prioriza o acesso à educação, principalmente ao ensino superior, apropriando-se do saber dominante, no intuito de utilizar, dentre os instrumentos existentes, o mais adequado na defesa de seus direitos e recuperar, assim, sua autonomia. (BAPTISTA, 2012). Diante deste cenário, torna-se urgente a implementação de políticas públicas, de longo e de curto prazo, que objetivem a inclusão de indígenas no corpo acadêmico superior. Nas palavras de Baptista (2012, p. 211), "pensar em ação afirmativa para povos indígenas consiste em tentar incluí-los no meio social. Não uma inclusão integracionista, que desrespeita o outro, mas uma inclusão que dá espaço, que deixa o outro ser ele mesmo (...)”.

Em tal contexto, o Supremo Tribunal Federal (STF) se pronunciou pela primeira vez em 2012 sobre a constitucionalidade dos programas de ação afirmativa baseados em critério etnicorracial para acesso ao ensino superior. No julgamento da Arguição de Descumprimento de Preceito Fundamental n. 186-2, a Corte decidiu que tais programas são compatíveis com a Constituição, porque realizam o princípio da igualdade material previsto na Carta da República.

Após a decisão do STF, passou a vigorar no ordenamento jurídico brasileiro a lei que institui o sistema de cotas nas universidades federais e instituições federais de ensino técnico de nível médio de todo o país. Trata-se da Lei n. 12.711, de 29 de agosto de 2012 (conhecida como Lei das Cotas), regulamentada pelo Decreto n. 7.824, de 11 de outubro de 2012.

A Lei prevê que as universidades federais e os institutos técnicos federais de nível médio reservem, no mínimo, 50\% das suas vagas para estudantes que tenham cursado integralmente o ensino médio, no caso das universidades, e o ensino fundamental, na hipótese das instituições de ensino técnico, em escolas públicas e que, no preenchimento dessas vagas, $50 \%$ deverão ser reservados aos estudantes oriundos de famílias com renda igual ou inferior a 1,5 salário-mínimo per capita.

As vagas destinadas aos alunos da escola pública serão também distribuídas entre os autodeclarados pretos, pardos e indígenas, em proporção no mínimo igual à desses grupos na população da unidade da Federação onde se localiza a instituição, segundo o último Censo do IBGE. Em caso de não preenchimento dessas vagas, aquelas remanescentes deverão ser completadas por estudantes provenientes da rede pública de ensino. 
A Lei 12.711 dispôs ainda que as universidades federais deverão implementar, no mínimo, 25\% da reserva de vagas nela previstas a cada ano, e terão o prazo máximo de 4 anos, a partir da data de sua publicação, para o seu cumprimento integral.

Como se verifica, tais disposições nortearão significativas mudanças em todas as universidades públicas federais e institutos técnicos federais no Brasil, justificando uma série de discussões nos próximos anos. Uma destas discussões refere-se exatamente às implicações que o modelo proposto para a reserva de vagas aos autodeclarados indígenas suscita, isto é, questões que dizem respeito à própria adequação e efetividade da medida afirmativa instituída pela Lei n. 12.711.

Nesta ordem de ideias, pretende-se analisar se os mecanismos e condições previstos na Lei das Cotas para o ingresso de estudantes indígenas nas instituições de ensino de nível técnico e superior são adequados e compatíveis às especificidades socioculturais deste grupo vulnerável, no sentido de possibilitar sua efetiva inclusão, e uma inclusão de qualidade, no corpo discente acadêmico.

\section{CONVENÇÃO 169 DA OIT E O MÉTODO DA AUTOIDENTIFICAÇÃO}

Em junho de 2002, após anos de tramitação, o Congresso Nacional ratificou a Convenção 169 da Organização Internacional do Trabalho (OIT) sobre Povos Indígenas e Tribais. ${ }^{8} \mathrm{O}$ documento internacional estabelece padrões mínimos a serem seguidos pelos Estados signatários relacionados aos direitos coletivos desses povos, reconhecendo suas aspirações "a assumir o controle de suas próprias instituições e formas de vida e seu desenvolvimento econômico, e manter e fortalecer suas identidades, línguas e religiões, dentro do âmbito dos Estados onde moram".

A Convenção 169 da OIT determina que o critério fundamental para determinar os grupos a que se aplicam as suas disposições deve ser a consciência indígena da própria identidade, conforme dispõe seu artigo $1^{\circ}$, item 2:

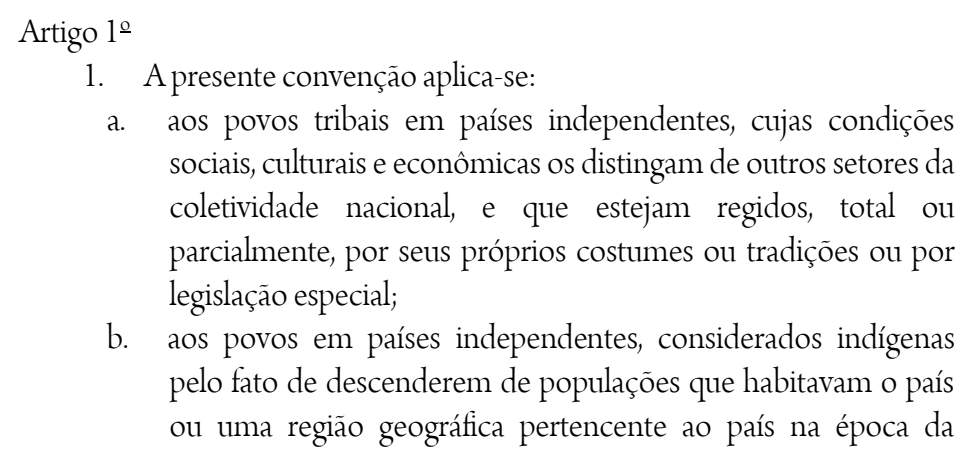

1. A presente convenção aplica-se:

a. aos povos tribais em países independentes, cujas condições sociais, culturais e econômicas os distingam de outros setores da coletividade nacional, e que estejam regidos, total ou parcialmente, por seus próprios costumes ou tradições ou por legislação especial;

b. aos povos em países independentes, considerados indígenas pelo fato de descenderem de populações que habitavam o país ou uma região geográfica pertencente ao país na época da

\footnotetext{
${ }^{8}$ A Convenção foi adotada na 76a Conferência Internacional do Trabalho, em 1989. Foi aprovada pelo Congresso Nacional por meio do Decreto Legislativo n. 143, de 20 de junho de 2002 - passando a vigorar no ordenamento jurídico brasileiro a partir de 25 de julho de 2003 - e promulgada pelo Decreto Presidencial n. 5.051, de 19 de abril de 2004.
} 
conquista ou da colonização ou do estabelecimento das atuais fronteiras estatais e que, seja qual for sua situação jurídica, conservam todas as suas próprias instituições sociais, econômicas, culturais e políticas, ou parte delas.A consciência de sua identidade indígena ou tribal deverá ser considerada como critério fundamental para determinar os grupos aos que se aplicam as disposições da presente Convenção. [grifo nosso]

De acordo com Guarany (2006), a expressão "consciência de sua identidade indígena" tem suscitado muitas controvérsias entre juristas, antropólogos e outros militantes da questão indígena, havendo pelo menos duas interpretações divergentes. De um lado, há aqueles que defendem a tese de que a autoidentificação é fator preponderante e exclusivo para a consciência da identidade indígena, excluindo, portanto, outros critérios. A outra interpretação possível é a que considera o princípio da autoidentificação como critério fundamental, sem, no entanto, excluir-se outros fatores, como o reconhecimento de pertença cultural pelo próprio grupo étnico.

O referido autor destaca que as políticas afirmativas para indígenas na área educacional têm trazido à tona situações nas quais o critério exclusivo da autoidentificação parece não responder satisfatoriamente. Muitos estudantes indígenas relatam seu descontentamento com as políticas de cotas das universidades que utilizam como único critério de acesso diferenciado a autodeclaração de pertencimento a um povo indígena, sem que haja a necessidade de apresentar documentos comprobatórios expedidos por lideranças comunitárias ou por associações indígenas. Tal ocorre, por exemplo, no Programa Universidade Para Todos (PROUNI), programa de bolsas do governo federal que constitui uma medida de ação afirmativa em relação aos povos indígenas e aos negros, o qual também só aplica o critério da autoidentificação. (GUARANY, 2006).

A exigência exclusiva da autodeclaração, segundo os estudantes indígenas, estaria permitindo ingresso de não-índios nas vagas destinadas aos índios e, assim, comprometendo a efetividade das medidas afirmativas criadas. Neste sentido, Guarany (2006, p. 155) sustenta que a consciência da identidade indígena implica a declaração individual aliada ao reconhecimento pelo grupo étnico de origem:

Assim, defendo a tese de que a definição sobre quem são os índios brasileiros dependerá da manifestação conjunta de vontades, tanto do grupo étnico quanto do indivíduo interessado. Se esses dois fatores operarem, o requisito da ascendência pré-colombiana automaticamente estará sendo cumprido, conforme comandos da Convenção 169, Artigo I, inciso b e do que está registrado na lei especial (Estatuto do Índio) em vigor no país.

Vale ressaltar que o art. 3º inciso I, do Estatuto do Índio diz que "[índio ou silvícola] é todo indivíduo de origem e ascendência pré-colombiana que se identifica e é identificado como pertencente a um grupo étnico cujas características culturais o distinguem da sociedade nacional".

Segundo Luciano (2006), a concepção que se tem acerca do papel da educação escolar nas comunidades indígenas, em todos os níveis de ensino, é determinante na escolha do método de identificação a ser utilizado nas políticas afirmativas voltadas a esses povos. Assim, se considerarmos a formação escolar não como um projeto individual do indígena, mas como estratégia de um projeto sociopolítico do qual o indivíduo é parte vol.08, nº.03, Rio de Janeiro, 2015. pp. 1369-1392 1380 
orgânica, o critério da autodeclaração torna-se inadequado. Neste caso, defende Luciano (2006), as coletividades indígenas devem ser o referencial para a identificação dos candidatos.

Beltrão, Oliveira e Oliveira (2009) explicam que pensar a identidade indígena em termos antropológicos e políticos remete à consideração de duas dimensões interconectadas: a coletiva e a individual. Pensada coletivamente, dizem os autores, a identidade indígena está relacionada com a noção de grupo, mais precisamente, de grupo social. No grupo, a ação cultural é tão somente consequência da ação coletiva, de forma que os grupos étnicos formam-se quando os indivíduos, com a finalidade de interação, fazem das identidades étnicas meios para se categorizar e categorizar os outros. No plano individual, trata-se da presença do sentimento pessoal de pertencimento a determinado grupo étnico, o que provoca, em resposta, o reconhecimento como membro pelo próprio grupo.

De acordo com Cunha e Beltrão (2012), em obra monográfica sobre o programa de reserva de vagas para povos indígenas da Universidade Federal do Pará (UFPA), a exigência feita pela instituição relativa à apresentação de comprovante de pertencimento à etnia indígena, emitido pelas autoridades políticas indígenas, caciques ou presidentes de associações indígenas, como requisito para a participação do candidato no processo seletivo especial, mostra-se coerente com as reivindicações do movimento indígena de que os estudantes contemplados pelas cotas revertam os conhecimentos adquiridos na academia em prol da comunidade. Dizem os autores:

O caráter coletivo da ação afirmativa estaria sendo contemplado na medida em que o benefício não é dirigido somente ao indígena estudante, e sim ao grupo, que valida as inscrições dos seus integrantes por meio do documento de pertença. Assim, o edital de seleção para as vagas reservadas, ao abraçar a pertença étnica como critério fundamental, está vislumbrando a necessidade de tal política beneficiar não somente um indivíduo, mas o grupo ao qual ele pertence.

O documento de pertença do indivíduo à comunidade deve ser pensado no processo de seleção como ferramenta adequada para selecionar os estudantes mais comprometidos em utilizar os conhecimentos advindos da graduação para colaborar com o desenvolvimento da comunidade que representa. (CUNHA e BELTRÃO, 2012, p. 25).

Diante destas considerações, é possível concluir que a consciência da identidade indígena, nos termos da legislação nacional e internacional, e no âmbito das políticas afirmativas, é mais adequadamente aferida a partir da conjugação de dois elementos: a declaração individual respaldada pelo documento de comprovação de pertencimento étnico emitido pela autoridade representante do grupo, posto que, no caso dos povos indígenas, as ações afirmativas são pensadas essencialmente para beneficiar sujeitos coletivos de direitos.

Reconhece-se, pois, que o critério da autoidentificação é um método que busca evitar identificações externas voltadas à discriminação negativa e fortalecer o reconhecimento da diferença, pois quem detém o poder de classificar o outro, pode fazer prevalecer seu próprio arbítrio. A efetivação do princípio do 
autorreconhecimento, no entanto, não pode estar dissociada do viés coletivo, isto é, do vínculo sociopolítico entre o sujeito individual e a sua comunidade, cabendo aos próprios membros do grupo étnico se autodefinirem e elaborarem seus próprios critérios de pertencimento e exclusão.

Embora a adoção de documento de pertença étnica emitida pelo representante da comunidade ou liderança indígena como critério de seleção possa gerar eventuais repercussões e conflitos internos na própria comunidade, conforme advertem Cunha e Beltrão (2012), os autores afirmam, não obstante, que este critério já vem sendo utilizado por outras instituições públicas brasileiras por se revelar o mais adequado para garantir a integridade e os objetivos dos programas de reserva de vagas para indígenas.

No estudo realizado por Beltrão, Oliveira e Oliveira (2009, p. 36), os autores refletem sobre o ponto de contato entre identidade e direitos indígenas no contexto das políticas afirmativas, destacando que a passagem da autopercepção identitária para o acesso a direitos de sujeitos específicos demanda uma operacionalização favorável às coletividades indígenas:

Ciente de que, em tempos de transição democrática pós-colonial, a liberdade dos indivíduos de definirem como se identificam não pode ser questionada, porém a passagem da auto-identificação para o acesso a direitos com destinatários específicos, especialmente no caso povos indígenas, necessariamente exige a utilização dos critérios legais de reconhecimento favoráveis as coletividades indígenas - fundamentalmente presentes no Convênio 169 -, portanto, a operacionalização do direito à autodeterminação para inclusão e participação social digna de povos historicamente excluídos e estereotipados por práticas coloniais ainda reproduzidas no cotidiano.

O fato de haver índios vivendo nas cidades - muitos dos quais migraram de suas aldeias em virtude da ausência de políticas públicas de saúde e educação que atendessem efetivamente às necessidades da comunidade indígena - não deve ser entendido como um dado revelador da perda da intenção de manter a condição de indígena. Araújo (2006, p. 241) explica que se trata de um fenômeno em geral resultado de processos de expulsão, que levou grupos inteiros, ou parte deles, a migrar das terras tradicionais para centros urbanos:

Exemplo disso é o caso dos índios pankararu, do sertão de Pernambuco, que em razão dos impasses no processo de demarcação de suas terras tradicionais, viram parte de sua população se deslocar para a cidade de São Paulo, onde se concentraram na Favela Real Parque [...], bem como em três outras áreas. Os pankararu tentam hoje reproduzir, no exíguo espaço da favela, a sua condição de povo, buscando manter traços mínimos de sua identidade cultural, seja como estratégia de sobrevivência em meio às difíceis condições da cidade grande, seja pela deliberada intenção de não quebrar os elos com a origem distante, que lhes garante a continuidade e a reprodução cultural. Situação semelhante enfrentam os índios do grupo Terena, que em razão da redução de seus territórios tradicionais, migraram em grande parte para Campo Grande, [...], onde chegam a constituir um bairro. Manaus, [...] e Boa Vista, [...], são outras duas cidades que receberam grandes contingentes de população indígena, que ali vivem ainda procurando manter os traços de suas identidades culturais. [grifo nosso] 
É importante esclarecer, portanto, que os índios citadinos não deixam de se reconhecer como índios, preservando seu sentimento de referência à origem ou sua identidade étnica num contexto de intenso intercâmbio cultural. Até porque, nas palavras de Luciano (2006, p. 49), "não existe cultura estática e pura, ela é sempre o resultado de interações e trocas de experiências e modos de vida entre indivíduos e grupos sociais", a significar que a interação com outras culturas não implica em perda da identidade étnica. Desse modo, é provável que a maioria dos índios que vivem fora das aldeias possa ser reconhecida por um povo indígena como pertencente ao grupo, por manter com este vínculos sociais, culturais, familiares e políticos.

Sob o ângulo deste complexo cenário de identidade étnica e suas fronteiras, passamos a analisar as diretrizes estabelecidas pela Lei n. 12.711 quanto ao critério de identificação dos candidatos indígenas. Observa-se que a lei fixou o método da autodeclaração individual, não prevendo expressamente a apresentação de nenhum documento comprobatório de pertença étnica emitido por autoridade indígena. O Decreto Regulamentador $\mathrm{n}$. 7.824/2012 e a Portaria Normativa n. 18/2012 do Ministério da Educação também silenciam sobre tal requisito.

No entanto, nada obsta que as universidades e os institutos técnicos federais, no âmbito de sua autonomia, exijam a declaração de pertença étnica assinada por liderança tradicional e/ou dirigente de associação indígena, que demonstre a vinculação social, cultural, política e familiar do candidato indígena com algum dos povos indígenas, em consonância com as disposições da Convenção 169 da OIT.

Neste sentido, vale ressaltar que a UFPA, desde 2009, adota política afirmativa consistente no acréscimo e na reserva de duas vagas, em todos os cursos da graduação, para serem ocupadas por integrantes de comunidades indígenas escolhidos via seleção diferenciada. ${ }^{9}$ A inscrição no processo seletivo é condicionada à apresentação de "comprovante de pertencimento à etnia indígena, emitido pelas autoridades políticas indígenas, caciques ou presidentes de associações indígenas". ${ }^{10}$

No primeiro Processo Seletivo Especial para Povos Indígenas realizado pela instituição após a vigência da Lei n. 12.711/2012 (PSE 2013-2), o edital do certame manteve a exigência da apresentação do referido comprovante de pertença étnica para a inscrição do candidato, nos seguintes termos:

$2.4 \mathrm{O}$ candidato indígena deverá entregar o Histórico Escolar do Ensino Médio (cópia do original), o Boleto de Pagamento gerado na inscrição e a Declaração de Pertencimento em um dos Campi indicados no item 1.4 deste Edital.

2.4.1 A Declaração de Pertencimento é o documento comprobatório que demonstra a vinculação social, cultural, política e familiar do candidato indígena com algum dos povos indígenas. Deve ser emitida e assinada por

\footnotetext{
9 Cf. UFPA. Resolução No. 3.869 - CONSEPE, de 22 de Junho de 2009. Disponível em: <http://www.ufpa.br/sege/boletim_interno/downloads/resolucoes/consepe/2009/Microsoft\%20Word\%20-\%203869.pdf s. Acesso em 16.07.13.

10 Cf. UFPA. Adendo ao Edital No. 1 - COPERPS, de 29 de Junho de 2009. Disponível em: <http://www.ceps.ufpa.br/daves/PSS2010/Adendo\%20Edital\%2001_2009_versao3.pdf $>$. Acesso em: 16.07.13.
} 
Autoridade indígena (liderança tradicional e/ou política e/ou dirigente de Associação Indígena), conforme previsto no Convênio No.169 da Organização Internacional do Trabalho (OIT) ratificado pelo Estado brasileiro. ${ }^{11}$ [grifos no original]

Mencione-se que, no endereço eletrônico do Ministério da Educação (MEC), há um espaço no qual são respondidas dúvidas frequentes relacionadas ao novo sistema de cotas. No que diz respeito ao critério racial, o órgão deixa entrever certa autonomia das instituições de ensino quanto ao estabelecimento de critérios adicionais específicos para candidatos indígenas:

10. Como será comprovada cor e renda declarados pelos candidatos? O critério da raça será autodeclaratório, como ocorre no censo demográfico e em toda política de afirmação no Brasil. Já a renda familiar per capita terá de ser comprovada por documentação, com regras estabelecidas pela instituição e recomendação de documentos mínimos pelo MEC.

11. No critério racial, haverá separação entre pretos, pardos e índios? Não. No entanto, o MEC incentiva que universidades e institutos federais localizados em estados com grande concentração de indígenas adotem critérios adicionais específicos para esses povos, dentro do critério da raça, no âmbito da autonomia das instituições. ${ }^{12}$

Nesta ordem de ideias, importa esclarecer que a Constituição Federal de 1988 consagrou o princípio da autonomia universitária no art. 207, in verbis: "As universidades gozam de autonomia didático-científica, administrativa e de gestão financeira e patrimonial, e obedecerão ao princípio de indissociabilidade entre ensino, pesquisa e extensão”. Por sua vez, a Lei n. 11.892/2008, que instituiu a Rede Federal de Educação Profissional, Científica e Tecnológica, dispõe no parágrafo único do art. 1º, cuja redação foi dada pela Lei no 12.677/2012, que os Institutos Federais de Educação, Ciência e Tecnologia - Institutos Federais "possuem natureza jurídica de autarquia, detentoras de autonomia administrativa, patrimonial, financeira, didático-pedagógica e disciplinar”.

Assim, verifica-se que tanto as universidades quanto os institutos técnicos federais possuem a natureza jurídica de autarquias, o que implica, segundo as lições de Di Pietro (2008, p. 409), “a capacidade de se autoadministrar a respeito das matérias específicas que lhes foram destinadas pela pessoa jurídica que lhes deu vida”.

Tratando especificamente da autonomia universitária, Durham (2005, p. 2) a define como "o reconhecimento de sua capacidade de reger-se por suas próprias normas no cumprimento das finalidades sociais às quais se destina”, de modo que é o papel social da universidade que dá os contornos da autonomia prevista no texto constitucional. Em relação à autonomia administrativa, a autora diz que esta decorre e é condição da autonomia didática e científica, conferindo liberdade à instituição para se organizar internamente, ou seja, para admitir alunos, ministrar cursos, conferir graus, realizar pesquisas etc. A autonomia administrativa compreende,

\footnotetext{
${ }^{11}$ Cf. UFPA. Edital n. 10 - COPERPS, de 19 de outubro de 2012. Disponível em: <http://ceps.ufpa.br/daves/PSE_2013\%20\%202/Edital\%20Indigenas\%20Revisado.pdf>. Acesso em: 16.07.13.

${ }^{12}$ Disponível em: <http://portal.mec.gov.br/cotas/perguntas-frequentes.html>. Acesso em: 16.07.13.
} 
pois, a competência da universidade para estabelecer a política geral voltada à consecução de suas metas institucionais. (DURHAM, 2005).

Neste sentido, a autonomia administrativa das universidades e dos institutos técnicos federais possui um caráter instrumental para o desempenho dos relevantes fins sociais atribuído a estas instituições de ensino. A capacidade de seu auto-gerir é indispensável à promoção da qualidade do ensino ministrado e das pesquisam que realizam, segundo o uso criterioso dos recursos públicos. Na qualidade de instituições públicas fomentadoras da inclusão social, têm competência para estabelecer os critérios de seleção dos seus alunos, em observância às suas metas institucionais.

À luz destas considerações, entende-se que as universidades e os institutos técnicos federais detêm certo grau de autonomia na implementação da Lei n. 12.711, o que possibilita a estas instituições de ensino exigir como requisito para a inscrição dos candidatos indígenas a apresentação de declaração de pertencimento emitida por autoridade indígena, consoante os parâmetros da Convenção 169 da OIT, vigente no ordenamento jurídico brasileiro.

Tal requisito se justifica, conforme visto, como um meio para garantir a adequação e a efetividade da medida afirmativa, considerando as peculiaridades e os anseios da população indígena, de modo a evitar que nãoindígenas tenham acesso às vagas reservadas. Afinal, além de haver a "necessidade de bem utilizar recursos valiosos e escassos, o que já é muito importante, [há também a preocupação] de evitar que essas iniciativas, que são justas, sejam abandonadas, exatamente porque não obedecem a critérios e, por isso, não funcionam”. (BRITO FILHO, 2013, p. 73).

\section{SELEÇÃO DIFERENCIADA. POLÍTICAS DE PERMANENCIA.}

Outro aspecto que merece reflexão em tema de políticas afirmativas na área da educação voltadas para povos indígenas, além do método de identificação dos candidatos, diz respeito ao meio de acesso para sua inclusão. A Lei n. 12.711, neste aspecto, apenas previu a reserva de vagas aos indígenas, não estabelecendo uma seleção diferenciada, que levasse em consideração as especificidades e a própria realidade da educação escolar indígena, a qual, conforme foi visto, não oferece um ensino de qualidade que capacite os estudantes a realizarem as provas tradicionais de seleção das universidades e das instituições federais que ofertam vagas de ensino técnico de nível médio.

Brito Filho (2013) adverte ser necessário que as medidas afirmativas contemplem instrumentos que garantam o acesso aos programas e a sua conclusão, a significar a adoção pelas universidades de meio de acesso compatível com o grupo que se pretende incluir, e condições objetivas para participação até o final. Desse modo, em relação aos povos indígenas, o autor sustenta que as instituições de ensino superior estabeleçam condições 
diferenciadas de acesso, sendo insuficiente a mera alocação de vagas, pois, devido à menor qualidade da educação escolar indígena ofertada nos níveis fundamental e médio, dificilmente os indígenas conseguiriam atingir o padrão mínimo estabelecido para todos os candidatos nos processos seletivos normais, chamado usualmente de "nota de corte". (BRITO FILHO, 2013).

Neste raciocínio, destaque-se a experiência desenvolvida pelo Programa de Pós-Graduação em Direito da Universidade Federal do Pará (PPGD/UFPA). Conforme relata Baptista (2012), inicialmente, o Programa reservou vagas específicas para indígenas, com processo seletivo idêntico para todos os candidatos de todas as vagas. Ao observar que a medida afirmativa até então aplicada era ineficiente, pois, nos dois primeiros processos seletivos com reserva de vagas para indígenas, estas não foram preenchidas, o PPGD/UFPA buscou outro tipo de ação afirmativa que fosse capaz de incluir indígenas no mestrado em Direito, implementando uma forma de seleção diferenciada. A mencionada autora explica então como se realizou tal seleção diferenciada para os candidatos indígenas:

Para se inscrever, além de outros documentos, era necessário que o candidato apresentasse pré-projeto de pesquisa, adequado à área de atuação do professor orientador, e indicação feita por Sociedade Indígena ou Organização Indígena. [...]. As fases de seleção - escolha do candidato para realizar nivelamento e, após aprovação, matrícula no programa - refletiram a preocupação no acesso e na adaptação do aluno, a fim de que ele estivesse apto a acompanhar o curso. Naquele ano [2006], foram preenchidas as duas vagas oferecidas, sendo selecionados dois discentes indígenas. (BAPTISTA, 2012, p. 212).

Assim, Baptista (2012) conclui que, por meio da seleção diferenciada, na qual eram observadas as peculiaridades inerentes aos povos indígenas e suas dificuldades naturais de acesso e permanência, foi possível alcançar o objetivo proposto de ingresso de estudantes indígenas na Pós-Graduação em Direito. É importante destacar que, no processo de seleção diferenciada do PPGD, os indígenas ingressam na condição de alunos especiais, passando inicialmente por um período de nivelamento, no qual são acompanhados por docentes que os auxiliam em suas dificuldades, caso existam. Se aprovado pelo orientador após essa etapa, o aluno é então matriculado no Programa e poderá creditar as disciplinas e seminários cursados. ${ }^{13} \mathrm{~A}$ etapa do nivelamento é, portanto, fundamental para que os estudantes indígenas tenham condições de acompanhar e concluir o curso com aproveitamento.

A experiência do PPGD/UFPA teve um êxito significativo - já formou dois mestres indígenas - e repercutiu inclusive na ampliação da medida afirmativa para a graduação de todos os demais cursos da UFPA, que, por meio da já mencionada Resolução n. 3.689, de 22 de junho de 2009, aprovou a reserva de duas vagas a indígenas, por acréscimo, nos cursos de graduação, mediante seleção diferenciada.

13 Cf. UFPA Programa de Pós-Graduação em Direito. Edital no 003/2006. Disponível em: <http://www.ufpa.br/juridico/documentos/Edital_03-2006_Selecao_PPGD_-_Diferenciado.pdf>.Acesso em: 18.07.13. 
No primeiro Processo Seletivo Especial para Povos Indígenas (PSE 2013-2) realizado pela instituição após a vigência da Lei n. 12.711/2012, manteve-se o processo de seleção diferenciada, o qual compreende duas fases: na primeira fase, o candidato realiza prova de língua portuguesa sob a forma de redação; na segunda, é entrevistado por uma comissão especial, que analisa o histórico escolar do ensino médio e a declaração de pertencimento. ${ }^{14}$

A reserva de vagas para indígenas nos cursos de graduação da UFPA, ao lado do seu preenchimento via seleção diferenciada, nos termos da Resolução n. 3.689/2009 da instituição, representou significativo avanço para a democratização do acesso ao ensino superior e a constituição de um corpo acadêmico plural e diversificado.

No entanto, Brito Filho (2013) adverte que a medida afirmativa em questão reúne poucas condições para ser eficaz, posto que a Resolução n. 3.689 não contemplou fontes de financiamento para a manutenção dos estudantes, que muitas vezes são obrigados a morar fora de suas aldeias, sem apoio financeiro. Além disso, não há qualquer previsão da criação de comissões destinadas a realizar o ajuste dos indígenas às exigências programáticas dos diversos cursos, podendo-se esperar dificuldades no acompanhamento pelos alunos. (BRITO FILHO, 2013). Em suma, a UFPA ainda se depara com o desafio de favorecer a permanência dos estudantes indígenas, de modo a concluírem com êxito a graduação.

Como foi dito acima, a Lei n. 12.711 apenas estabeleceu a reserva de vagas para indígenas, sem prever qualquer espécie de seleção diferenciada que levasse em conta as peculiaridades e a realidade precária da educação escolar básica ofertada a esse grupo vulnerável. Assim, o meio de acesso às universidades e aos institutos técnicos federais para os candidatos indígenas em nada difere do meio de acesso previsto para todos os outros candidatos, consistente em processos seletivos segundo os quais há a eliminação do candidato que não atinge o rendimento mínimo exigido ou "nota de corte". Logo, é provável que muitas das vagas reservadas para indígenas nestas instituições de ensino sequer sejam preenchidas, comprometendo sobremaneira a efetividade da política afirmativa instituída pela lei.

O Decreto n. 7.824/2012, que regulamenta a Lei n. 12.711, dispõe no seu art. 1º, parágrafo único, que "os resultados obtidos pelos estudantes no Exame Nacional do Ensino Médio - ENEM poderão ser utilizados como critério de seleção para o ingresso nas instituições federais vinculadas ao Ministério da Educação que ofertam vagas de educação superior" (grifo nosso). A Portaria n. 18 do MEC, no seu art. 3º, parágrafo único, repete tal disposição. Vale destacar que o $\$ 2^{\circ}$ do art. 10 dessa Portaria estipula que:

Diante das peculiaridades da população do local de oferta das vagas, e desde que assegurado o número mínimo de vagas reservadas à soma dos pretos, pardos e indígenas da unidade da Federação do local de oferta de vagas,

\footnotetext{
${ }^{14}$ Cf. UFPA. Edital n. 10 - COPERPS, de 19 de outubro de 2012. Disponível em: <http://ceps.ufpa.br/daves/PSE_2013\%20\%202/Edital\%20Indigenas\%20Revisado.pdf>. Acesso em: 18.07.13.
} 
apurado na forma deste artigo, as instituições federais de ensino, no exercício de sua autonomia, poderão, em seus editais, assegurar reserva de vagas separadas para os indígenas. (grifo nosso)

A partir destas regras legais, depreende-se, portanto, que as instituições federais de ensino (universidades e institutos técnicos), na implementação do novo sistema de cotas, poderão, diante das peculiaridades da população local, reservar vagas extras para os indígenas, isto é, além daquelas já previstas pela Lei n. 12.711. Esta regulação é importante, porque reconhece a necessidade de as instituições federais de ensino superior e de nível médio procederem a uma modulação dos regramentos gerais fixados na lei das cotas às distintas realidades socioculturais do grupo vulnerável, desde que assegurado o cumprimento dos padrões mínimos da lei.

Ademais, em relação ao ingresso nas universidades, verifica-se que a utilização dos resultados obtidos pelos estudantes no ENEM como critério de seleção é facultativa, detendo as universidades autonomia para escolher a forma de admissão dos seus alunos e, em especial, dos alunos indígenas. Do mesmo modo, as instituições federais que ofertam vagas de ensino técnico de nível médio, na condição de autarquias, são autônomas para definirem como se realizará seus processos seletivos.

Neste sentido, embora a Lei n. 12.711 não tenha previsto expressamente a realização de seleção diferenciada para os estudantes indígenas, entende-se que as instituições de ensino federais detêm autonomia para adequar, nos limites legais, a aplicação do sistema de cotas às diferentes realidades locais. Por conseguinte, verificado que as vagas reservadas aos estudantes indígenas não estão sendo preenchidas, porque os alunos não estão atingindo o rendimento mínimo exigido nas provas aplicadas, é possível e recomendável a utilização de um mecanismo diferenciado de acesso a ser aplicado a este grupo, que contemple as especificidades e as dificuldades derivadas da educação escolar básica indígena.

De outro lado, não basta somente garantir o acesso à universidade ou ao ensino técnico de nível médio aos indígenas. É preciso que os estabelecimentos de ensino assegurem a permanência do estudante indígena no curso, dando suporte até a sua conclusão, pois, caso contrário, de nada serviria a adoção da política afirmativa. Muitos alunos têm de sair de suas aldeias, enfrentando dificuldades econômicas para se manter nas cidades, sem mencionar as barreiras didático-pedagógicas que podem vir a sentir durante as aulas. Destaque-se, neste sentido, as iniciativas do governo federal para garantir a permanência dos estudantes cotistas na universidade, conforme informações divulgadas no endereço eletrônico do MEC:

12. Como o governo federal vai garantir a permanência dos estudantes cotistas na universidade?

A política de assistência estudantil será reforçada. No orçamento de 2013 já está previsto um aumento para o Programa Nacional de Assistência Estudantil (Pnaes). Serão investidos pelo menos R \$ 600 milhões em assistência estudantil em 2013. O MEC está articulando com os reitores a 
política de acolhimento dos alunos cotistas, que também gira em torno da política de tutoria e nivelamento. ${ }^{15}$

Por meio da Portaria n. 389, de 9 de maio de $2013^{16}$, o MEC criou o Programa de Bolsa Permanência (PBP), destinado à concessão de auxílio financeiro a estudantes matriculados em instituições federais de ensino superior, com o objetivo de viabilizar a permanência, no curso de graduação, de estudantes em situação de vulnerabilidade socioeconômica, em especial os indígenas e quilombolas.

De acordo com o art. $4^{\circ}, \$ 2^{\circ}$, da citada Portaria, a bolsa concedida aos estudantes indígenas e quilombolas será diferenciada, em virtude das especificidades desses estudantes com relação à organização social de suas comunidades, condição geográfica, costumes, línguas, crenças e tradições, amparadas pela Constituição Federal.

Ressalte-se ainda que, nos termos da Portaria n. 389, a comprovação da condição de estudante indígena se dará através da apresentação dos seguintes documentos: a) autodeclaração do candidato; b) declaração de sua respectiva comunidade sobre sua condição de pertencimento étnico, assinada por pelo menos três lideranças reconhecidas; c) declaração da FUNAI de que o estudante indígena reside em comunidade indígena ou comprovante de residência em comunidade indígena.

\section{CONCLUSÕES}

A reserva de vagas para estudantes indígenas nas universidades e nos institutos técnicos federais instituída pela Lei n. 12.711/2012 representou um importante passo para a promoção da igualdade de oportunidades no acesso à educação de nível superior e de nível médio a povos etnicamente diferenciados, os quais foram, durante séculos de colonialismo, excluídos e segregados.

A política afirmativa em questão beneficia não apenas os grupos indígenas, mas o ambiente acadêmico com um todo, na medida em que, ao reconhecer e valorizar a diversidade sociocultural, possibilita a convivência com as diferenças e a interação entre conhecimentos e cosmologias distintos, contribuindo, portanto, para a superação de estereótipos e preconceitos.

Não obstante, a fim de que a medida surta os efeitos esperados, no sentido de promover a efetiva inclusão social do grupo vulnerável, mediante uma eficaz utilização dos recursos disponíveis, é preciso que os critérios adotados pelas instituições de ensino para o acesso dos indígenas às vagas reservadas sejam compatíveis à realidade e às especificidades desses povos.

\footnotetext{
${ }^{15}$ Disponível em: <http://portal.mec.gov.br/cotas/perguntas-frequentes.html>. Acesso em: 20.07.13.

16 Disponível em: <http://prae.ufsc.br/files/2013/06/2013.05.09-Portaria-389-MEC-2013-Cria\%C3\%A7\%C3\%A3o-doPrograma-Bolsa-Perman\%C3\%AA>ncial.pdf $>$. Acesso em: 20.07.13.
} 
Neste sentido, em relação ao método de identificação dos indígenas, propõe-se que as universidades e institutos técnicos, no âmbito de sua autonomia, exijam como requisito para a inscrição dos candidatos, ao lado da autodeclaração estabelecida pela Lei n. 12.711, a apresentação de declaração de pertencimento emitida por autoridade indígena, consoante os parâmetros da Convenção 169 da OIT, vigente no ordenamento jurídico brasileiro, de modo a evitar que não-indígenas tenham acesso às cotas.

De modo semelhante, uma vez que as universidades e os institutos técnicos possuem autonomia para definir a forma de ingresso dos seus alunos, propõe-se a adoção de um processo diferenciado de seleção para os indígenas, caso constatado que as vagas reservadas aos integrantes desse grupo não estão sendo preenchidas, em razão das dificuldades que enfrentam para atingir o rendimento mínimo exigido nos processos seletivos tradicionais.

Após o ingresso do aluno indígena na universidade ou no instituto técnico, é fundamental que receba apoio institucional, consistente no oferecimento de bolsas e na realização do "nivelamento", a fim de que tenha condições objetivas de concluir com êxito o curso, podendo, assim, reverter os conhecimentos adquiridos em benefício do seu grupo étnico.

\title{
AFFIRMATIVE ACTION AND INDIGENOUS PEOPLES: ISSUES ON THE IMPLEMENTATION OF LAW No. 12,711 / 2012 BY THE FEDERAL EDUCATION INSTITUTIONS
}

\begin{abstract}
In this article, we analyze the vacancies reservation system established by Law. N. 12,711 / 2012 for indigenous peoples in universities and federal technical institutes. In the context of affirmative policies to this vulnerable group and the claims of the Brazilian indigenous movement, it discusses the space left by Law n. 12,711 for the performance of the federal educational institutions in order to adjust the indigenous entry criteria specific characteristics of the people in order to make adequate and effective affirmative action. In this sense, it is proposed that universities and middle-level technical institutes in the framework of its autonomy, can adopt the method of identifying the candidates according to the parameters of ILO Convention 169 as well as perform differentiated selection process for indigenous students .
\end{abstract}

Keywords: Indigenous peoples. Affirmative action. Law n. 12,711 / 2012. ILO Convention 169. Differentiated selection. 


\section{REFERENCIAS}

ARAÚJO, Ana Valéria (et alii). Povos indígenas e a "lei dos brancos": o direito à diferença. Brasília: Ministério da Educação, Secretaria de Educação Continuada, Alfabetização e Diversidade; LACED/Museu Nacional, 2006. Disponível em: <http://www.trilhasdeconhecimentos.etc.br/livros/arquivos/ColET14_Vias03WEB.pdf> Acesso em: 03.07.13.

Povos indígenas e igualdade étnico-racial. In: BRASIL, Secretaria Especial de Políticas da Promoção da Igualdade Racial da Presidência da República - SEPPIR. Ordem jurídica e igualdade étnico-racial. Brasília: SEPPIR, 2006.

BAPTISTA, Lia Raquel Ventura. Ações afirmativas: ensino superior aos povos indígenas. In: NETO, Antonio José de Mattos; NETO, Homero Lamarão; SANTANA, Raimundo Rodrigues (orgs). Direitos humanos e democracia inclusiva. São Paulo: Saraiva, 2012.

BELTRÃO, Jane Felipe; OLIVEIRA, Assis da Costa; OLIVEIRA, Leon da Costa. Outras faces do ser indígena: entre pertencimentos e exclusões. In: Espaço Ameríndio. Porto Alegre, v. 3, n. 2., jul./dez. 2009. p. 15-16. Disponível em: <http://www.seer.ufrgs.br/index.php/EspacoAmerindio/article/view/10777/6988>. Acesso em: 14.07.13.

BRASIL. Supremo Tribunal Federal. Acórdão na Argüição de descumprimento de preceito fundamental n. 186/DF. Relator: Ricardo Lewandowski. Publicado no DJ de 20.10.2014. Disponívelem: $<$ http: $/ /$ www.stf.jus.br/portal/processo/verProcessoAndamento.asp?incidente=2691269 >.

Acesso em: 21.02.15.

BRITO FILHO, José Cláudio Monteiro de. Ações Afirmativas. 2ª ed. São Paulo: Ltr, 2013.

CUNHA, Mainá Jailson Sampaio; BELTRÃO, Jane Felipe. Povos indígenas, universidade e programa de reserva de vagas: implantação e tentativas de fraude. Belém/PA: UFPA, 2012. Monografia (Bacharelado em Direito), Faculdade de Direito, Universidade Federal do Pará, 2012.

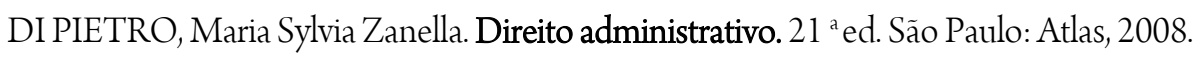

DURHAM, Eunice Ribeiro. A autonomia universitária: o princípio constitucional e suas implicações. Núcleo de Pesquisas sobre Ensino Superior. Universidade de São Paulo. Disponível em: <http://nupps.usp.br/downloads/docs/dt8909.pdf>. Acesso em: 17.07.13.

GOMES, Joaquim B. Barbosa. Ação afirmativa e princípio constitucional da igualdade: o direito como instrumento de transformação social. A experiência dos EUA. Rio de Janeiro: Renovar, 2001.

GUARANY, Vilmar Martins Moura. Desafios e perspectivas para a construção e o exercício da cidadania indígena. In: ARAÚJO, Ana Valéria (et alii). Povos indígenas e a "lei dos brancos": o direito à diferença. Brasília: Ministério da Educação, Secretaria de Educação Continuada, Alfabetização e Diversidade; LACED/Museu Nacional, 2006.2 Disponível em: <http://www.trilhasdeconhecimentos.etc.br/livros/arquivos/ColET14_Vias03WEB.pdf> Acesso em: 03.07.13.

LUCIANO, Gersem dos Santos. O índio brasileiro: o que você precisa saber sobre os povos indígenas no Brasil de hoje. Brasília: Ministério da Educação, Secretaria de Educação Continuada, Alfabetização e Diversidade; 
LACED/Museu Nacional, $2006 . \quad$ Disponível em: <http://www.trilhasdeconhecimentos.etc.br/livros/arquivos/ColET12_Vias01WEB.pdf >. Acesso em: 29.06.13.

PIOVESAN, Flávia. Direito internacional dos direitos humanos e igualdade étnico-racial. In: PIOVESAN, Flávia e SOUZA, Douglas Martins de (coordenadores). Ordem jurídica e igualdade étnico-racial. Brasília: SEPPIR, 2006.

SANTILLI, Juliana. Socioambientalismo e novos direitos. São Paulo: Peirópolis, 2005.

SANTOS, Boaventura de Sousa. A construção intelectual da igualdade e da diferença. In: SANTOS, Boaventura de Sousa. A gramática do tempo: para uma nova cultura política. São Paulo: Cortez, 2006.

SOUZA FILHO, Carlos Frederico Marés de. O Renascer dos Povos indígenas para o Direito. Curitiba: Juruá, 1998.

Trabalho enviado em 22 de fevereiro de 2015.

Aceito em 03 de maio de 2015. 